\title{
Differences in Individual and Dyadic Coping Among Low and High Depressed, Partially Remitted, and Nondepressed Persons
}

\author{
Guy Bodenmann, ${ }^{1,3}$ Linda Charvoz, ${ }^{1}$ Kathrin Widmer, ${ }^{1}$ and Thomas N. Bradbury ${ }^{2}$
}

\begin{abstract}
Accepted September 3, 2003
Investigations of the individual and interpersonal coping resources of depressed persons are underrepresented in the field of research on depression. Whereas some studies have been conducted on depressed couples evaluating individual coping or social support from others, only a few studies have addressed the topic of dyadic coping, or the way both partners cope together. In the present effort, male and female participants with a current or past diagnosis of depression, all of whom were married or cohabiting in a close relationship, reported on their individual and dyadic coping and were compared on these variables with a matched group of control participants. Results corroborate previous findings on deficits in individual coping, and to a lesser degree in dyadic coping.
\end{abstract}

KEY WORDS: depression; coping; dyadic coping; social support.

Many studies demonstrate that depressed persons show dysfunctional cognitive processes with regard to expectancies, attribution processes, and perception of situations (e.g., Abramson, Seligman, \& Teasdale, 1987; Barnett \& Gotlib, 1988; Beck, Rush, Shaw, \& Emery, 1979; Haaga, Dyck, \& Ernst, 1991; Metalsky \& Joiner, 1992; Peterson \& Seligman, 1984). Recognition of these deficits set the stage for a series of studies on how depressed individuals cope with stressful events and circumstances (see Bruder-Mattson \& Hovanitz, 1990), with findings indicating that depression ${ }^{4}$ covaries significantly with dysfunctional coping strategies both on the cognitive as

\footnotetext{
${ }^{1}$ University of Fribourg (Switzerland), Institute for Family and Counseling, Fribourg, Switzerland.

${ }^{2}$ University of California, Los Angeles, California.

${ }^{3}$ To whom correspondence should be addressed at University of Fribourg (Switzerland), Institute for Family Research and Counseling, Avenue de la gare 1, CH-1700 Fribourg, Switzerland; e-mail: Joseguy.bodenmann@unifr.ch.

${ }^{4}$ Despite recent research describing unipolar depression as a trouble with multiple facets and subforms, depression is treated in this article as a diagnostic category according to DSM-IV and is not distinguished among different subtypes with regard to distinct characteristics such as etiological or process factors. It is evident that this view does not reflect the complexity of depression and is limited.
}

well as on the behavioral level. Cognitive coping strategies that have been found to be associated with depression are rumination, negative meta-cognitive beliefs, self-blaming, and wishful thinking (Billings \& Moos, 1984; Coyne, Aldwin, \& Lazarus, 1981; Mitchell, Cronkite, \& Moos, 1983; Papageorigou \& Wells, 2003). Among these dysfunctional cognitive coping strategies, rumination seems to play a predominant role in adults as well as in adolescents (Kraaij et al., 2003). It is noteworthy that rumination, and specifically stress-reactive rumination, which is found to be correlated with depression in most studies, appears to predict the prospective onset of a depressive episode (Robinson \& Alloy, 2003).

With regard to behavioral coping strategies, several studies show that depressed individuals are more likely than nondepressed individuals to engage in passivity, avoidance, and escape behavior and to display less problem-solving coping (Coyne et al., 1981; Cronkite, Moos, Twohey, Cohen, \& Swindle, 1998; Rohde, Tilson, Lewinsohn, \& Seely, 1990). However, Blalock and Joiner (2000) revealed that, among women, coping via cognitive avoidance moderated the association between life events and depression, whereas coping via behavioral avoidance did not. Along similar lines, research shows that depressed persons tend to appraise stress in a relatively 
generalized fashion (Folkman \& Lazarus, 1986) and that their appraisals and goals are relatively inflexible and less appropriate for the handling of the stressful encounter (Billings \& Moos, 1984; Gotlib \& Whiffen, 1989; Perrez $\&$ Reicherts, 1986). In sum, investigations of individual coping capacities indicate a considerable gap between the subjective appraisals made by depressed individuals and the coping responses they generate and enact and the objective demands of the situations and circumstances that confront them.

Apart from these findings on shortcomings in individual coping, several studies report that depression is associated also with deficiencies in social resources (e.g., Coyne, 1976) and social support from friends and family members (e.g., Dehle, Larsen, \& Landers, 2001; Gotlib, 1982). By showing that social support from family members or friends covaries inversely with the severity of depression symptoms (Lakey \& Cassady, 1990, report a correlation of $r=-.45$ ) and predicts a faster and more complete recovery from depression (e.g., Barnett \& Gotlib, 1988; Coiro \& Gottesman, 1996; Coyne et al., 1987; George, Blazer, Hughes, \& Fowler, 1989; Husaini \& Von Frank, 1985; Keitner \& Miller, 1990; Lara, Leader, \& Klein, 1997; Moos, Cronkite, \& Moos, 1998), this research corroborates the notion that social support plays an important role in understanding depression in close relationships. This is not to imply, however, that the effects of social support are unique to depression, as they are apparent in many other psychological and medical disorders. The results of the longitudinal study by Moos et al. (1998; see also Henderson, 1992) suggest, moreover, that deficits in interpersonal resources (i.e., a lack of social support) are often not a consequence of the affective disorder but instead appear to be present prior to the onset of depression. In their 10-year longitudinal study, Cronkite et al. (1998) found that fewer close relationships were an important predictor of no positive change (nonremission).

Although much is known about the role of individual coping and social support deficits in depression, much less is known about the social support provided by the partner in close relationships. In many studies, social support from others (friends, parents, siblings) is combined with social support from the intimate partner. As a result, the unique role of support from intimate partners is difficult to discern. This is an important problem, because an intimate relationship is often the primary interpersonal context for individuals struggling with depression. Large bodies of related work exist on marital quality and depression (e.g., Banawan, O'Mahen, Beach, \& Jackson, 2001; Beach, Sandeen, \& O'Leary, 1990; Fincham, Beach, \& Bradbury, 1989; Johnson \& Jacob, 1997; McCabe \& Gotlib, 1993; Sandberg \& Harper, 2000; Sayers, Kohn,
Fresco, Bellack, \& Sarwer, 2001) and on such constructs as "expressed emotion" and negativity in dyadic interaction (e.g., Florin, Nostadt, Reck, Franzen, \& Jenkins, 1992; Hooley \& Hahlweg, 1986; Hooley, Orley, \& Teasdale, 1986; Hooley \& Teasdale, 1989; Vaughn \& Leff, 1976). These studies document a clear link between affective disorder and distress in relationships, yet they reveal little specifically about the role of social support in depression.

Among the few studies conducted on social support in this domain, Monroe, Connell, Bromet, and Steiner (1986) found that reports of social support provided by the partner covary on the order of -.37 with symptoms of depression. Similarly, Dew and Bromet (1991) showed that wives who became depressed within a span of 12 months, received less social support initially from their spouse than did controls. Whereas these two studies address the question of how the depressed patients are supported by significant others, some recent research also investigates the inverse pattern. Horesh and Fennig (2000), for example, reported that being married to a patient who suffered from depression was negatively correlated with the way the well partner perceived the support he or she received from the spouse.

In addition to addressing individual coping, this study emphasizes the concept of dyadic coping which has been developed by Bodenmann $(1995,1997)$. According to this view, three forms of positive dyadic coping behaviors and three forms of negative dyadic coping behaviors are distinguished. The three forms of positive dyadic coping are, first, problem- and emotion-focused supportive dyadic coping. Here, one partner assists the other in his or her coping efforts through a variety of activities, such as practical help with daily tasks, providing advice, empathic understanding of the partner's stress, attending to and showing interest in his or her problems, helping the partner to reframe the situation, helping the partner to relax and slow down, communicating a belief in the partner's capabilities, and expressing solidarity with the partner. Second, problem- and emotion-focused common dyadic coping is evident in the form of joint problem solving, coordinated handling of demands, mutual calming, mutual sharing of feelings, mutual solidarity, and relaxing together. Third, delegated dyadic coping is characterized by one partner taking over several tasks to reduce the stress experienced by his or her mate, as when, for example, one partner does the shopping instead of the other to reduce some of the partner's stress.

Negative dyadic coping is distinguished by the following three types of coping behaviors. First, ambivalent dyadic coping occurs when one partner supports the other unwillingly and with no real motivation and interest, or with the attitude that he or she should not really have to 
offer support. Hostile dyadic coping involves the support that is accompanied by disparagement, distancing, mocking or sarcasm, open disinterest, or minimizing the seriousness of the partner's stress. Finally, superficial dyadic coping consists of support that is insincere or not genuine. This is exemplified by asking questions about the partner's stress without listening to what he or she is saying or supporting the partner without real empathy and sincerity.

As dyadic coping has been shown to be a powerful predictor of marital functioning (Bodenmann, 2000), it may prove fruitful to extend this concept to couples with a depressed patient. The present study aimed to do so, by assessing individual and dyadic coping resources in a sample of 66 depressed patients, 40 partially remitted patients (in total 106 currently or previously depressed), and 106 matched controls (all married). It was hypothesized that patients with high depression scores exhibit significantly lower individual and dyadic coping resources than patients with a low depression score, partially remitted patients, or controls.

\section{METHOD}

\section{Participants}

Participants were 106 depressed or formerly depressed patients and 106 matched controls. All participants were either married or in an intimate relationship for at least 1 year. The depressed and partially remitted patients were recruited from three major psychiatric clinics and 12 outpatient service centers in Switzerland between April and December, 2001. All patients were diagnosed or had been diagnosed with major depression (code 296.2) by psychiatrists according to $D S M-I V$ criteria (using the SCID; Spitzer, Williams, Gibbon, \& First, 1992). Unfortunately, there are no data on diagnostic reliability (e.g., interrater reliability among psychiatrists); however, the BDI scores presented in Table I provide evidence to support the validity of the psychiatrists' classifications. Patients were ineligible for participation if they exhibited psychotic symptoms, symptoms of bipolar disorder, or another psychological disorder. Independent diagnostic interviews were not possible, but patient responses on the Beck Depression Inventory (BDI; Beck, Ward, Mendelson, Mock, \& Erbaugh, 1961) were used to validate diagnoses (see Table I).

Participants in the control group were recruited from local communities using newspaper advertisements and were matched to the three patient groups on age, sex, educational level, and relationship satisfaction (as assessed with the PFB; Hahlweg, 1996; see Table I) to ensure that there were no differences between depressed and control participants on these variables. All participants in the control group were required to score below the BDI cut-off value of 11 points, indicating no depressive symptoms (see Table I).

Analyses of variance on age, $F(3,207)=1.7 ; n s$, and relationship satisfaction (PFB total score: $F(3,207)=.56$; $n s$, and chi-square analyses on education, $\chi^{2}(4)=2.7 ; n s$, indicated that matching procedures were successful.

\section{Procedure}

Names and addresses of patients meeting study criteria were communicated to the research team by clinic staff. A research team member then informed eligible patients, in person or by telephone, about the study, and they were asked whether they would be willing to participate in the project. People expressing interest in the study at this point received a brochure containing detailed information about the project and a consent form and were instructed to sign and return the consent form to the University of Fribourg (Switzerland), Institute of Family Research and Counseling if they were interested in participating further. Of the total patients who met inclusion criteria and expressed interest in the study, $47.4 \%$ participated. No demographic data were collected on eligible patients who did not participate, and differences between responders and nonresponders could not be examined. Upon receipt of the signed consent forms, participants and their partners then received a mailed packet of questionnaires, with instructions to complete them without consulting one another and to return the forms to the institute within 2 weeks. Very similar procedures were used with individuals recruited for the control group. This report presents data collected from patients and matched controls. Data from partners are not reported.

\section{Questionnaires}

\section{Demographic Variables}

Participants provided information on their age, sex, marital status, relationship duration, relationship satisfaction, type of residence, number of children, religion, education, profession, and percentage of employment.

\section{Beck Depression Inventory (BDI)}

The BDI (Beck et al., 1961) is a 21-item selfreport scale that assesses affective, cognitive, and somatic 
Table I. Descriptive Statistics on Sociodemographic Variables for Control, Partially Remitted, Low Depression and High Depression Participants

\begin{tabular}{|c|c|c|c|c|c|c|c|c|c|c|c|c|}
\hline \multirow[b]{2}{*}{ Women } & \multicolumn{3}{|c|}{$\begin{array}{l}\text { Controls } \\
(n=62)\end{array}$} & \multicolumn{3}{|c|}{$\begin{array}{l}\text { Partially remitted } \\
\quad(n=20)\end{array}$} & \multicolumn{3}{|c|}{$\begin{array}{l}\text { Low depression } \\
\quad(n=22)\end{array}$} & \multicolumn{3}{|c|}{$\begin{array}{l}\text { High depression } \\
\quad(n=20)\end{array}$} \\
\hline & $M$ & $S D$ & Range & $M$ & $S D$ & Range & $M$ & $S D$ & Range & $M$ & $S D$ & Range \\
\hline BDI & 4.61 & 3.30 & $0-11$ & 6.65 & 3.91 & $0-11$ & 15.55 & 2.39 & $12-19$ & 25.18 & 5.81 & $20-43$ \\
\hline Duration of relationship & 16.07 & 9.60 & $1-53$ & 19.32 & 11.03 & $2-44$ & 19.25 & 11.79 & $1-40$ & 18.65 & 12.52 & $2-42$ \\
\hline \multicolumn{13}{|c|}{ Percentage $(\%)$} \\
\hline \multicolumn{13}{|l|}{ Age } \\
\hline 20-30 & & 4.8 & & & 5.0 & & & 9.1 & & & 5.3 & \\
\hline $31-40$ & & 46.8 & & & 40.0 & & & 36.4 & & & 36.8 & \\
\hline $41-50$ & & 33.9 & & & 35.0 & & & 22.7 & & & 21.1 & \\
\hline More than 50 & & 14.5 & & & 20.0 & & & 31.8 & & & 36.8 & \\
\hline \multicolumn{13}{|l|}{ Marital status } \\
\hline Married & & 96.7 & & & 95.0 & & & 81.8 & & & 95.0 & \\
\hline Not married & & 3.3 & & & 0.0 & & & 13.6 & & & 5.0 & \\
\hline Separated/divorced & & 0.0 & & & 5.0 & & & 4.5 & & & 0.0 & \\
\hline $\begin{array}{l}\text { Living in common } \\
\text { household }\end{array}$ & & 93.4 & & & 95.0 & & & 90.9 & & & 100.0 & \\
\hline Children education & & 82.3 & & & 85.0 & & & 76.2 & & & 80.0 & \\
\hline Elementary school & & 10.0 & & & 5.0 & & & 4.5 & & & 10.0 & \\
\hline High school & & 51.6 & & & 55.0 & & & 59.1 & & & 60.0 & \\
\hline College & & 28.3 & & & 20.0 & & & 22.7 & & & 25.0 & \\
\hline \multirow[t]{2}{*}{ University } & & 10.0 & & & 20.0 & & & 13.6 & & & 5.0 & \\
\hline & \multicolumn{3}{|c|}{$(n=44)$} & \multicolumn{3}{|c|}{$(n=20)$} & \multicolumn{3}{|c|}{$(n=11)$} & \multicolumn{3}{|c|}{$(n=13)$} \\
\hline Men & $M$ & $S D$ & Range & $M$ & $S D$ & Range & $M$ & $S D$ & Range & $M$ & $S D$ & Range \\
\hline BDI & 3.82 & 2.86 & $0-11$ & 5.30 & 4.03 & $0-11$ & 14.27 & 2.20 & $12-19$ & 30.38 & 9.53 & $20-53$ \\
\hline Duration of relationship & 19.00 & 11.76 & $1-56$ & 21.06 & 11.45 & $4-43$ & 18.45 & 7.29 & $1-29$ & 22.55 & 9.15 & $9-36$ \\
\hline \multicolumn{13}{|c|}{ Percentage $(\%)$} \\
\hline \multicolumn{13}{|l|}{ Age } \\
\hline $20-30$ & & 0.0 & & & 0 & & & 0.0 & & & 0.0 & \\
\hline $31-40$ & & 22.7 & & & 10.0 & & & 0.0 & & & 15.4 & \\
\hline $41-50$ & & 54.5 & & & 55.0 & & & 72.7 & & & 53.8 & \\
\hline More than 50 & & 22.7 & & & 35.0 & & & 27.3 & & & 30.8 & \\
\hline \multicolumn{13}{|l|}{ Marital status } \\
\hline Married & & 97.7 & & & 90.0 & & & 90.9 & & & 92.3 & \\
\hline Not married & & 2.3 & & & 5.0 & & & 0.0 & & & 7.7 & \\
\hline Separated/divorced & & 0.0 & & & 5.0 & & & 9.1 & & & 0.0 & \\
\hline $\begin{array}{l}\text { Living in common } \\
\text { household }\end{array}$ & & 93.2 & & & 100.0 & & & 90.9 & & & 84.6 & \\
\hline Children education & & 81.8 & & & 95.0 & & & 90.9 & & & 84.6 & \\
\hline Elementary school & & 2.3 & & & 0.0 & & & 0.0 & & & 0.0 & \\
\hline High school & & 37.2 & & & 55.0 & & & 63.6 & & & 23.1 & \\
\hline College & & 23.3 & & & 30.0 & & & 9.1 & & & 46.2 & \\
\hline University & & 37.2 & & & 15.0 & & & 27.3 & & & 30.8 & \\
\hline
\end{tabular}

aspects of depression. It is the most frequently used self-report instrument for assessing depression severity and demonstrates good psychometric properties. A metaanalysis of the BDI's internal consistency revealed a mean coefficient alpha of .86 for psychiatric patients and .81 for nonpsychiatric persons. Scale scores are highly correlated with clinical ratings (e.g., the Hamilton Psychiatric Rating
Scale for Depression) with $r=.72$ to .73 . The gender bias of the instrument is low, and the BDI discriminates reliably between subtypes of depression and differentiates depression from anxiety disorders (Beck, Steer, \& Carbin, 1988). Participants respond to the items on a 4-point scale $(0-3)$. According to German cut-off values reported by Hautzinger, Bailer, Worall, and Keller (1994), scores over 
12 reflect irritability associated with depression, scores over 20 are consistent with mild depression, and scores over 26 may indicate severe depression. Cronbach's alpha on the BDI was .93 in this study.

\section{Individual Coping Questionnaire (INCOPE-2)}

Developed on the basis of the COPE (Carver, Scheier, $\&$ Weintraub, 1989), this 23 -item questionnaire yields six subscales derived from factor analysis that reflect a variety of individual coping strategies (Bodenmann, 2000). All items are answered on 5-point scales $(1=$ never, $5=$ always), with respect to the frequency with which the different coping strategies are used in everyday life. The six subscales assess Rumination (intellectual brooding, avoiding the topic, feelings of guilt; 4 items; $\alpha=.70$ ); Positive Self-Verbalization (positive outlook on future, change of values, self meditation; 3 items; $\alpha=.74$ ); Active Problem Solving (active engagement, brainstorming, active search for social support; 7 items; $\alpha=.71$ ); Expression of Negative Emotions (expression of negative feelings, blaming the partner; 3 items; $\alpha=.73$ ); Negative Relaxation Strategies (smoking, alcohol consumption, excessive television viewing; 3 items; $\alpha=.75$ ); and Withdrawal/Avoidance (avoiding the stress event, repressing the stressful encounter; 3 items; $\alpha=.86$ ). Cronbach's alpha for the entire scale is .72. Previous validational studies on the INCOPE demonstrate adequate concurrent and predictive validity (e.g., Bodenmann, 2000).

\section{Dyadic Coping Questionnaire (FDCT-N)}

This is a 55-item questionnaire that assesses dyadic coping and communication under conditions of stress. Respondents answer questions regarding "What you do when you are feeling stress," "What your partner does when you are feeling stress," "What you do when your partner is feeling stress," and "What you and your partner do when you both feel stress." In this study, the following scales of the FDCT-N were used: Stress Communication (telling the partner about the stress experience, asking the partner for emotional or practical support; 5 items; $\alpha=.80$ ); Supportive Dyadic Coping by Oneself (empathy, understanding, comforting the partner, helping the partner to reframe the situation, helping the partner to relax, practical advice or help; 13 items; $\alpha=.85$ ); Supportive Dyadic Coping of the Partner (same items as for oneself but with partner as actor; 13 items; $\alpha=.91$ ); and Common Dyadic Coping (facing the stressful event together, common relaxation exercises, mutual comforting, exchange of rele- vant information on the stress event; 10 items; $\alpha=.83$ ). Furthermore, negative dyadic coping (hostile and ambivalent dyadic coping; criticizing the partner while supporting him/her, minimizing the stress of the partner, helping the partner but without real interest or empathy) was assessed with four items for oneself $(\alpha=.75)$ and the partner $(\alpha=.78)$. Persons rated frequency of dyadic coping on a scale $(0=$ never, $5=$ always $)$. The criterion and construct validity of the FDCT-N have been previously evaluated (Bodenmann, 2000). Cronbach's alpha was .92 for the entire scale.

\section{Partnership Questionnaire \\ (Partnerschaftsfragebogen; PFB)}

The PFB (Hahlweg, 1996) is a 31-item instrument used to measure marital quality and satisfaction and consists of three scales: Quarreling $(\alpha=.93)$, Tenderness $(\alpha=.91)$, and Togetherness/Communication $(\alpha=.88)$. These can be combined to create a total score of marital quality $(\alpha=.95)$, with scores below 54 designating low levels of satisfaction, scores between 55 and 72 corresponding to medium levels of satisfaction, and scores 73 and above corresponding to high levels of martial satisfaction. The total score discriminates reliably between distressed and nondistressed couples, allows close monitoring of changes in marital therapy, and demonstrates adequate reliability and validity (Hahlweg, 1996). This questionnaire was used only for matching the groups on marital quality, to circumvent the common problem of relationship satisfaction confounding comparisons between depressed and nondepressed participants.

\section{Assignment of Participants to Groups}

For the subsequent statistical analyses, four groups were used. Apart from the Control group (first group), three groups within the depressed sample were formed according to their BDI score (on the basis of the German norms of cut-off-scores; cf. Hautzinger et al., 1994). Whereas Partially Remitted participants (second group) were required to have a BDI score below the cut-off score of 11 points, participants with Low Depression (third group) reported a BDI score between 12 and 20. The fourth group represented Medium to High Depressed patients with a BDI-score above 21, although most participants in this group scored above 25 , thus indicating severe depression. All analyses were conducted separately for women and men. Whereas there were no significant differences 
between groups with regard to age, education, and marital quality, the four groups differed significantly on the BDI, Group: $F(3,209)=285.7 ; p<.001$; Sex: $F(1$, $211)=.46 ; n s ;$ Group $\times$ Sex: $F(3,208)=5.03 ; p<.002$. Scheffé tests showed that there were significant differences on BDI scores between Control and Partially Remitted participants in comparison to the groups with Low and High Depression $(p<.001)$, whereas Controls and Partially Remitted participants did not differ $(p=.19)$. However, patients with Low and High Depression differed reliably with regard to their depression score $(p<.001)$. Whereas male patients reported lower depression scores than women in the Partially Remitted and Low Depression groups, men scored higher on the BDI than women labelled High Depression.

\section{RESULTS}

Correlations were computed to assess the degree of association among and between the individual and dyadic coping subscales (see Table II). Subscales within instruments tended to be reliably correlated, as expected, yet appeared to have sufficient unique variance so that meaningful analysis of the subscales was possible. Correlations between the instruments tended to be lower, and the majority of these correlations (44 of 72) were nonsignificant.

There were some important exceptions-INCOPE assessments of Problem-Solving tended to covary with FDCT-N subscales, as did INCOPE assessments of Positive Self-Verbalization, particularly for men, yet there appeared to be sufficient independence to examine individual and dyadic coping as separate concepts. This was supported further by nonsignificant correlations between total scores on the INCOPE and the FDCT-N $(r=.08$; $n s)$.

\section{Individual Coping}

To evaluate possible differences in individual coping between the four groups (Controls, Partially Remitted, Low Depression, High Depression), $4 \times 2$ (Group $\times$

Table II. Intercorrelations Among and Between the Subscales of the INCOPE and the FDCT

\begin{tabular}{|c|c|c|c|c|c|c|}
\hline & 1 & 2 & 3 & 4 & 5 & 6 \\
\hline \multicolumn{7}{|l|}{ INCOPE } \\
\hline Rumination & & $-.53^{* * * *} /-.33^{* *}$ & $*-.34^{* * * *} /-.35^{* * * *}$ & $.50^{* * * *} / .30^{* * *}$ & $.32^{* * * * *} / .20^{*}$ & $.24^{* * *} / .42^{* * * *}$ \\
\hline $\begin{array}{l}\text { Positive self- } \\
\text { verbalization }\end{array}$ & & & $.53^{* * * * *} / .66^{* * * *}$ & $-.26^{* * *} /-.06$ & $-.18^{* *} /-.02$ & $.03 /-.01$ \\
\hline Problem-solving & & & & $-.24^{* * *} /-.19^{*}$ & $-.23^{* *} / .03$ & $-.17 * /-.24 * *$ \\
\hline $\begin{array}{l}\text { Negative relaxation } \\
\text { strategies }\end{array}$ & & & & & $.40^{* * * *} / .24^{* *}$ & $.20^{* *} / .42^{* * * *}$ \\
\hline Negative em. expression & & & & & & $.03 / .31^{* * *}$ \\
\hline \multicolumn{7}{|l|}{ Avoidance } \\
\hline \multicolumn{7}{|l|}{ FDCT } \\
\hline Stress communication & & $.37^{* * * *} / .58^{* * * *}$ & $.39^{* * * *} / .59^{* * * *}$ & $-.17^{*} /-.21^{*}$ & $-.31^{* * * *} / .14$ & $.38^{* * * *} / .56^{* * * *}$ \\
\hline Own supportive DC & & & $.59^{* * * *} / .69^{* * * *}$ & $-.24^{* * *} /-.35^{* * * *}$ & $-.31^{* * * *} /-.01$ & $.53^{* * * *} / .65^{* * * *}$ \\
\hline Partner supportive DC & & & & $-.30^{* * * *} /-.41^{* * * *}$ & $-.49^{* * * * *} /-.11$ & $.63^{* * * *} / .63^{* * * *}$ \\
\hline Own negative DC & & & & & $.51^{* * * *} / .59^{* * * *}$ & $-.30^{* * * *} /-.49^{* * * *}$ \\
\hline Partner negative DC & & & & & & $-.45^{* * * *} /-.11$ \\
\hline \multicolumn{7}{|l|}{ Common DC } \\
\hline & Rumination & $\begin{array}{c}\text { Positive } \\
\text { self- } \\
\text { verbalization }\end{array}$ & $\begin{array}{c}\text { Problem- } \\
\text { solving }\end{array}$ & $\begin{array}{c}\text { Negative } \\
\text { emotional } \\
\text { expression }\end{array}$ & $\begin{array}{c}\text { Negative } \\
\text { relaxation } \\
\text { strategies }\end{array}$ & $\begin{array}{l}\text { Withdrawal/ } \\
\text { avoidance }\end{array}$ \\
\hline \multicolumn{7}{|l|}{ INCOPE-FDCT } \\
\hline Stress communication & $-.19^{* *} /-.18$ & $.14 / .47^{* * * * *}$ & $.38^{* * *} / .46^{* * * *}$ & $-.24^{* * *} /-.20$ & $-.25^{* * *} /-.12$ & $-.25^{* * *} /-.13$ \\
\hline Own supportive DC & $-.05 /-.28^{* * *}$ & $.15 / .60^{* * * * *}$ & $.32^{* * * *} / .52^{* * * *}$ & $-.23^{* *} /-.24^{* *}$ & $-.10 /-.14$ & $.03 /-.12$ \\
\hline Partner supportive DC & $-.05 /-.19^{*}$ & $.06 / .47^{* * * *}$ & $.32^{* * *} / .41^{* * *}$ & $-.14 /-.23^{* *}$ & $.02 /-.04$ & $.06 /-.04$ \\
\hline Own negative DC & $-.07 / .06$ & $.16 * /-.14$ & $.05 /-.05$ & $.22^{* *} / .30^{* * *}$ & $.06 / .12$ & $.06 / .03$ \\
\hline Partner negative DC & $.03 /-.12$ & $.13 / .14$ & $-.10 / .27^{* *}$ & $.14 / .22^{* *}$ & $.16 /-.02$ & $.06 /-.10$ \\
\hline Common DC & $-.06 /-.33^{* * *}$ & $-.10 / .50^{* * * *}$ & $.29^{* * * *} / .51^{* * * *}$ & $-.21^{* *} /-.36^{* * * *}$ & $-.03 /-.13$ & $-.08 /-.29^{* * *}$ \\
\hline
\end{tabular}

Note. In each cell, the first correlation coefficient represents the correlation for women, the second represents the correlation for men. DC $=\mathrm{Dy} a d i c$ coping.

${ }^{*} p<.10 .^{* *} p<.05 .^{* * *} p>.01 .{ }^{* * * *} p \leq .001$. 
Gender) multivariate analyses of variance were conducted for the six INCOPE-2 subscales, followed by ANOVAs. As shown in Table III, a significant multivariate effect for group was obtained, indicating that the four groups differed on individual coping. The ANOVAs show that there were significant differences on all subscales, indicating that Controls and Partially remitted persons showed significantly higher scores in Positive Self-Verbalization and Problem-Solving, whereas dysfunctional coping strategies such as Rumination, Negative Relaxation Strategies (e.g., smoking, excessive eating), Negative Emotional Expression, and Avoidance were reported less often in these two groups. There were no differences between Controls and Partially Remitted persons. Main effects for sex were obtained on several variables, but these were comparable across groups (i.e., there were no Group $\times$ Sex effects; see Table III).

As the Scheffé tests revealed, differences were found between High Depression and Control participants for women and for men in most of the individual coping strategies, except Negative Emotional Expression in women and Positive Self-Verbalization, Problem-Solving, and Negative Emotional Expression in men. Whereas men in the Low Depression group did not differ significantly from the other groups except in Rumination, women with Low Depression showed more Rumination and Negative Emotional Expression and marginally less Positive SelfVerbalization. Partially Remitted patients and Control participants did not differ when men were compared, but Partially Remitted women reported more Rumination than Control women (see Table IV).

\section{Dyadic Coping}

Multivariate analysis of the FDCT-N variables also yielded a significant multivariate effect, indicating differences among groups in dyadic coping. The ANOVAs illustrate several group effects with regard to Stress Communication, Own Supportive Dyadic Coping, Common Dyadic Coping, and Own and Partner's Negative Dyadic Coping (see Table V).

As the Scheffé tests illustrate, differences were obtained primarily between women in the High Depression and Control groups. Highly depressed women reported lower scores in Stress Communication and in Own Supportive Dyadic Coping, compared to the Controls and

Table III. Differences in Individual Coping in Controls and Partially Remitted, Low Depression, and High Depression Patients

\begin{tabular}{|c|c|c|c|c|c|c|c|c|}
\hline & \multicolumn{2}{|c|}{ Controls $(n=62)$} & \multicolumn{2}{|c|}{ Partially remitted $(n=20)$} & \multicolumn{2}{|c|}{ Low depression $(n=22)$} & \multicolumn{2}{|c|}{ High depression $(n=20)$} \\
\hline & $M$ & $S D$ & $M$ & $S D$ & $M$ & $S D$ & $M$ & $S D$ \\
\hline \multicolumn{9}{|l|}{ Women } \\
\hline Rumination & 3.07 & 0.56 & 3.51 & 0.78 & 3.78 & 0.51 & 4.12 & 0.49 \\
\hline Positive self-verbalization & 3.39 & 0.84 & 3.18 & 0.91 & 2.82 & 0.81 & 2.53 & 0.96 \\
\hline Problem-solving & 3.33 & 0.58 & 3.31 & 0.70 & 3.10 & 0.43 & 2.89 & 0.60 \\
\hline Negative relaxation strategies & 2.18 & 0.61 & 2.49 & 0.67 & 2.50 & 0.83 & 3.13 & 0.71 \\
\hline Negative emotional expression & 2.19 & 0.55 & 2.65 & 0.61 & 2.65 & 0.78 & 2.48 & 0.75 \\
\hline \multirow[t]{2}{*}{ Avoidance } & 2.46 & 0.85 & 2.75 & 0.72 & 2.82 & 0.91 & 3.45 & 1.05 \\
\hline & \multicolumn{2}{|c|}{$n=44$} & \multicolumn{2}{|c|}{$n=20$} & \multicolumn{2}{|c|}{$n=11$} & \multicolumn{2}{|c|}{$n=13$} \\
\hline \multicolumn{9}{|l|}{ Men } \\
\hline Rumination & 2.71 & 0.64 & 2.86 & 0.86 & 3.75 & 0.60 & 4.06 & 0.39 \\
\hline Positive self-verbalization & 3.08 & 0.99 & 3.23 & 1.00 & 2.76 & 0.54 & 2.67 & 0.88 \\
\hline Problem-solving & 3.06 & 0.63 & 3.07 & 0.77 & 2.78 & 0.51 & 2.66 & 0.66 \\
\hline Negative relaxation strategies & 2.08 & 0.62 & 2.18 & 0.82 & 2.42 & 0.78 & 2.92 & 0.91 \\
\hline Negative emotional expression & 1.97 & 0.51 & 2.03 & 0.72 & 1.94 & 0.74 & 2.26 & 0.61 \\
\hline \multirow[t]{2}{*}{ Avoidance } & 2.75 & 0.81 & 3.05 & 1.15 & 3.36 & 0.92 & 4.15 & 0.69 \\
\hline & \multicolumn{3}{|c|}{ Group effect } & \multicolumn{3}{|c|}{ Sex effect } & \multicolumn{2}{|c|}{ Group $\times$ Sex effect } \\
\hline Rumination & \multicolumn{3}{|c|}{$37.86^{* * * *}$} & \multicolumn{3}{|c|}{$7.76^{* * *}$} & \multicolumn{2}{|c|}{1.98} \\
\hline Positive self-verbalization & \multicolumn{3}{|c|}{$5.33^{* * * *}$} & \multicolumn{3}{|c|}{0.12} & \multicolumn{2}{|c|}{0.75} \\
\hline Problem-solving & \multicolumn{3}{|c|}{$4.81^{* * *}$} & \multicolumn{3}{|c|}{$7.39^{* * *}$} & \multicolumn{2}{|c|}{0.04} \\
\hline Negative relaxation strategies & \multicolumn{3}{|c|}{$13.32^{* * * *}$} & \multicolumn{3}{|c|}{2.41} & \multicolumn{2}{|c|}{0.26} \\
\hline Negative emotional expression & \multicolumn{3}{|c|}{$2.91^{* *}$} & \multicolumn{3}{|c|}{$20.00^{* * * *}$} & \multicolumn{2}{|c|}{1.86} \\
\hline Avoidance & \multicolumn{3}{|c|}{$15.18^{* * * *}$} & \multicolumn{3}{|c|}{$10.78^{* * * *}$} & \multicolumn{2}{|c|}{0.55} \\
\hline
\end{tabular}

Note. Multivariate effects: Group: $F(6,200)=25.32^{* * *}$; Sex: $F(6,198)=8.19^{* * *}$; Group $\times$ Sex: $F(6,200)=1.62, n s$.

${ }^{*} p<.10{ }^{* *} p<.05 .^{* * *} p<.01 .^{* * * *} p<.001$. 
Table IV. Pairwise Comparisons Between Groups on Individual Coping Variables, for Women and Men

\begin{tabular}{lccccrr}
\hline & Hi-Ctl & Lo-Ctl & Rem-Ctl & Hi-Rem & Lo-Rem & Hi-Lo \\
\hline Women & & & & & & \\
$\quad$ Rumination & $1.05^{* * * *}$ & $0.71^{* * * *}$ & $0.45^{* *}$ & $0.60^{* *}$ & 0.27 & 0.34 \\
Positive self-verbalization & $-0.86^{* * *}$ & $-0.58^{* *}$ & -0.21 & -0.65 & -0.37 & -0.28 \\
Problem-solving & $-0.45^{* *}$ & -0.23 & -0.03 & -0.42 & -0.20 & -0.22 \\
Negative relaxation strategies & $0.95^{* * * *}$ & 0.32 & 0.31 & $0.64^{* *}$ & 0.01 & $0.63^{* *}$ \\
Negative emotional expression & 0.29 & $0.46^{*}$ & $0.46^{*}$ & -0.17 & 0.00 & -0.17 \\
Avoidance & $0.99^{* * * *}$ & 0.36 & 0.29 & $0.70^{* *}$ & 0.07 & 0.63 \\
Men & & & & & & \\
Rumination & $1.34^{* * * *}$ & $1.04^{* * * *}$ & 0.15 & $1.20^{* * * *}$ & $0.89^{* * *}$ & 0.31 \\
Positive self-verbalization & -0.41 & -0.32 & 0.16 & -0.57 & -0.48 & -0.09 \\
Problem-solving & -0.40 & -0.28 & 0.01 & -0.41 & -0.29 & -0.12 \\
Negative relaxation strategies & $0.84^{* * *}$ & 0.34 & 0.10 & $0.74^{*}$ & 0.24 & 0.50 \\
Negative emotional expression & 0.29 & -0.03 & 0.06 & 0.22 & -0.09 & 0.32 \\
Avoidance & $1.40^{* * * *}$ & 0.61 & 0.30 & $1.10^{* * *}$ & 0.31 & 0.79 \\
\hline
\end{tabular}

Note $. \mathrm{Ctl}=$ Control; $\mathrm{Rem}=$ Partially remitted Lo $=$ Low depression; $\mathrm{Hi}=$ High depression. Contrasts were conducted using Scheffé tests.

${ }^{*} p<.10 .^{* *} p<.05 .^{* * *} p<.01 .^{* * * *} p<.001$.

Partially Remitted participants. Female patients in the Low Depression group also differed from Controls with regard to Stress Communication. Male depressed patients, on the other hand, reported marginally higher scores on Own Negative Dyadic Coping than Controls (see Table VI).

\section{DISCUSSION}

This study examined differences in individual and dyadic coping among groups of high and low depressed, partially remitted, and nondepressed persons. It was hypothesized that deficits in individual and dyadic coping would be highest in the highly depressed group, because this group should be characterized by fewer subjectively available coping resources. The results support this hypothesis and confirm prior studies which have shown that depression is associated with deficits in individual coping, mainly with regard to rumination, negative relaxation strategies, and avoidance in both sexes (Billings \& Moos, 1984; Coyne et al., 1981; Cronkite et al., 1998; Folkman \& Lazarus, 1986; Gotlib \& Whiffen, 1989; Mitchell et al., 1983; Parker, Brown, \& Blignault, 1986), and in social support (Barnett \& Gotlib, 1988; Coiro \& Gottesman, 1996; Hammen, 1991; Henderson, 1992). Depressed women also reported communicating their stresses less often to their partner and engaging less frequently in supportive dyadic coping with their partner. High depressed men described marginally more negative dyadic coping behavior towards their partner.

This study confirms that coping deficits exist especially in high depressed persons, mainly at the individual level but somewhat as well at the dyadic level in women. However, the data reveal that dysfunctional individual coping was more evident than deficits in dyadic coping, where subgroup comparisons did not yield many differences. This finding is especially interesting as it indicates that depressed patients did not respond to all measures with a negative bias but instead were able to differentiate among the different variables on the individual and dyadic level. This means that even the High Depressed participants did not evaluate all coping categories in a generalized and negative manner (which could have been assumed according to Beck's theory) but that their appraisals were differentiated and thus probably valid.

There are limitations of this study. The first concerns its cross-sectional, self-report nature. This design limits the inferences that can be drawn, and the study leaves some essential questions opened and unanswered, such as the question of causality. A common question among researchers is whether these deficits are a cause of depression or whether they are merely a consequence or correlate. To answer this question, longitudinal research is indispensable. However, there is some evidence that deficits may already be observed before the onset of depression. For example, a 10-year-longitudinal study by Moos et al. (1998), involving a sample of 313 participants with clinically depressive symptoms, demonstrated that deficits in social support are evident prior to depressive episodes. These results are similar to those of Holahan and Moos (1991) who reported in a 4-year-longitudinal study involving a community sample of 254 persons that initial resources (i.e., psychological resources and family support) had a causal link to the depressive episodes at different time points. 
Table V. Differences in Dyadic Coping in Controls and Partially Remitted, Low Depression, and High Depression Patients

\begin{tabular}{|c|c|c|c|c|c|c|c|c|}
\hline & \multicolumn{2}{|c|}{ Controls $(n=62)$} & \multicolumn{2}{|c|}{ Partially remitted $(n=20)$} & \multicolumn{2}{|c|}{ Low depression $(n=22)$} & \multicolumn{2}{|c|}{ High depression $(n=20)$} \\
\hline & $M$ & $S D$ & $M$ & $S D$ & $M$ & $S D$ & $M$ & $S D$ \\
\hline \multicolumn{9}{|l|}{ Women } \\
\hline Stress communication & 4.12 & 0.70 & 3.86 & 0.80 & 3.58 & 0.85 & 3.32 & 0.93 \\
\hline Own supportive DC & 3.81 & 0.73 & 3.98 & 0.58 & 3.59 & 0.79 & 3.27 & 0.83 \\
\hline Partner supportive DC & 3.66 & 0.84 & 3.64 & 0.70 & 3.31 & 0.65 & 3.33 & 1.02 \\
\hline Own negative DC & 1.78 & 0.42 & 1.67 & 0.49 & 1.93 & 0.74 & 1.94 & 0.68 \\
\hline Partner negative DC & 1.96 & 0.67 & 2.10 & 0.74 & 2.33 & 0.81 & 2.43 & 0.89 \\
\hline \multirow[t]{2}{*}{ Common DC } & 3.19 & 0.61 & 3.38 & 0.69 & 3.18 & 0.51 & 2.87 & 0.76 \\
\hline & \multicolumn{2}{|c|}{$n=44$} & \multicolumn{2}{|c|}{$n=20$} & \multicolumn{2}{|c|}{$n=11$} & \multicolumn{2}{|c|}{$n=13$} \\
\hline \multicolumn{9}{|l|}{ Men } \\
\hline Stress communication & 3.53 & 0.55 & 3.52 & 1.15 & 3.47 & 0.63 & 3.07 & 0.89 \\
\hline Own supportive DC & 3.85 & 0.87 & 3.88 & 0.97 & 3.61 & 0.41 & 3.46 & 0.75 \\
\hline Partner supportive DC & 3.48 & 0.89 & 3.41 & 1.25 & 3.84 & 0.86 & 3.12 & 0.67 \\
\hline Own negative DC & 1.80 & 0.52 & 1.97 & 0.61 & 1.83 & 0.69 & 2.28 & 0.61 \\
\hline Partner negative DC & 1.67 & 0.54 & 1.83 & 0.65 & 1.80 & 0.72 & 2.17 & 0.96 \\
\hline \multirow[t]{2}{*}{ Common DC } & 3.28 & 0.77 & 3.35 & 1.02 & 3.35 & 0.50 & 2.72 & 0.36 \\
\hline & \multicolumn{3}{|c|}{ Group effects } & \multicolumn{3}{|c|}{ Sex effect } & \multicolumn{2}{|c|}{ Group $\times$ Sex effect } \\
\hline Stress communication & \multicolumn{3}{|c|}{$5.51^{* * * *}$} & \multicolumn{3}{|c|}{$6.57^{* *}$} & \multicolumn{2}{|c|}{.93} \\
\hline Own supportive DC & \multicolumn{3}{|c|}{$3.94^{* * *}$} & \multicolumn{3}{|c|}{.08} & \multicolumn{2}{|c|}{.21} \\
\hline Partner supportive DC & \multicolumn{3}{|c|}{1.31} & \multicolumn{3}{|c|}{.02} & \multicolumn{2}{|c|}{1.35} \\
\hline Own negative DC & \multicolumn{3}{|c|}{$2.71^{* *}$} & \multicolumn{3}{|c|}{2.45} & \multicolumn{2}{|c|}{1.43} \\
\hline Partner negative DC & \multicolumn{3}{|c|}{$3.96^{* * *}$} & \multicolumn{3}{|c|}{$8.64^{* * *}$} & \multicolumn{2}{|c|}{.26} \\
\hline Common DC & \multicolumn{3}{|c|}{$4.60^{* * *}$} & \multicolumn{3}{|c|}{.03} & \multicolumn{2}{|c|}{.36} \\
\hline
\end{tabular}

Note $. \mathrm{DC}=$ Dyadic coping; Multivariate effects: Group: $F(5,200)=4.94^{* * *}$; Sex: $F(5,198)=4.34^{* * *}$; Group $\times$ Sex: $F(5,200)=1.59$. ${ }^{*} p<.10{ }^{* *} p<.05 .{ }^{* * *} p<.01 .^{* * * *} p<.001$.

Although recent research has partially confirmed the role of social support in the development and maintenance of depression, clarification of the individual and dyadic coping resources is needed to develop a more elaborate understanding of these deficits. This study aids in this regard, particularly by showing that levels of depression are associated with dysfunctional individual coping resources and some deficits in dyadic coping (with regard to

Table VI. Pairwise Comparisons Between Groups on Dyadic Coping Variables, for Women and Men

\begin{tabular}{lcrrrrr}
\hline & Hi-Ctl & Lo-Ctl & Rem-Ctl & Hi-Rem & Lo-Rem & Hi-Lo \\
\hline Women & & & & & & \\
Stress communication & $-0.81^{* * *}$ & $-0.54^{*}$ & -0.26 & -0.54 & -0.28 & -0.27 \\
Own supportive DC & $-0.54^{* *}$ & -0.22 & 0.17 & $-0.72^{* *}$ & -0.39 & -0.32 \\
Partner supportive DC & -0.33 & -0.35 & -0.02 & -0.31 & -0.33 & 0.02 \\
Own negative DC & 0.16 & 0.15 & -0.11 & 0.27 & -0.26 & 0.01 \\
Partner negative DC & -0.47 & 0.37 & 0.14 & 0.33 & 0.23 & 0.09 \\
Common DC & -0.32 & -0.01 & 0.19 & $-0.52^{*}$ & -0.20 & -0.31 \\
Men & & & & & & \\
Stress communication & -0.46 & -0.06 & -0.01 & -0.45 & -0.04 & -0.41 \\
Own supportive DC & -0.39 & -0.24 & 0.03 & -0.42 & -0.27 & -0.15 \\
Partner supportive DC & -0.36 & 0.35 & -0.07 & -0.29 & 0.42 & -0.71 \\
Own negative DC & $0.48^{*}$ & 0.02 & 0.17 & 0.31 & -0.15 & 0.46 \\
Partner negative DC & 0.50 & 0.13 & 0.16 & 0.33 & -0.03 & 0.37 \\
Common DC & -0.56 & 0.08 & 0.07 & -0.63 & 0.00 & -0.64 \\
\hline
\end{tabular}

Note . $\mathrm{DC}=$ Dyadic coping; $\mathrm{Ctl}=\mathrm{Control} ; \mathrm{Rem}=$ Partially remitted $;$ Lo $=$ Low depression $; \mathrm{Hi}=\mathrm{High}$ depression. Contrasts were conducted using Scheffé tests.

${ }^{*} p<.10{ }^{* *} p<.05 .{ }^{* * *} p<.01 .^{* * * *} p<.001$. 
stress communication and own supportive dyadic coping in women and own negative dyadic coping in men). In contrast to a previous study with a smaller sample of clinically depressed patients (Bodenmann, Cina, \& Schwerzmann, 2001), the present findings could not replicate that the support depressed individuals report from their partners is frequently perceived as more ambivalent or hostile and as less effective and satisfying. Therefore, more studies are necessary to investigate dyadic coping in depressed samples.

Notwithstanding the reliance on self-report data, and the possibility that self-reports may be biased systematically among depressed patients (cf. Gara et al., 1993), the present work indicates that depressed individuals experience broad deficiencies mainly in individual and to a lesser degree in dyadic coping. Clinical implications may be drawn cautiously from these findings, yet it might be speculated that within therapy it may be useful to incorporate more coping resources as a supplement to pure cognitive therapy (Beck et al., 1979; cf. McLean \& Hakstian, 1990). At the same time that efficient individual coping is emphasized in treatment, involvement of the partner into the treatment can also be considered, to make this important source of support more effective (e.g., Beach et al., 1990). It is suggested that it can be beneficial to focus on two issues: first to enhance coping skills of depressed persons in addition to cognitive restructuring, and second to include the partner in the treatment of individuals with depression. Although more research on these issues is needed, it is encouraging to see that a growing number of scholars have become interested in coping processes. It is, however, important to address coping not only on the individual level but also within the couple.

\section{ACKNOWLEDGMENT}

This study was supported by a research grant of the Swiss National Science Foundation SNF 610-062901.

\section{REFERENCES}

Abramson, L. Y., Seligman, M. E. P., \& Teasdale, J. D. (1987). Learned helplessness in humans: Critique and reformulation. Journal of $A b$ normal Psychology, 87, 49-74.

Banawan, S. F., O'Mahen, H. A., Beach, S. R. H., \& Jackson, M. H. (2001). The empirical underpinnings of marital therapy for depression. In J. H. Harvey \& A. Wenzel (eds.), A clinician's guide to maintaining and enhancing close relationships (pp. 133-155). Mahwah, NJ: Erlbaum.

Barnett, P. A., \& Gotlib, I. H. (1988). Psychological functioning and depression: Distinguishing among antecedents, concomitants, and consequences. Psychological Bulletin, 104, 97-126.
Beach, S. R. H., Sandeen, E. E., \& O'Leary, K. D. (1990). Depression in marriage: A model for etiology and treatment. New York, NY: Guilford.

Beck, A. T., Rush, A. J., Shaw, B. F., \& Emery, G. (1979). Cognitive therapy of depression. New York, NY: Guilford.

Beck, A. T., Steer, R. A., \& Carbin, M. G. (1988). Psychometric properties of the Beck Depression Inventory: Twenty-five years of evaluation. Clinical Psychology Review, 8, 77-100.

Beck, A. T., Ward, C., Mendelson, M., Mock, J., \& Erbaugh, J. (1961). An inventory for measuring depression. Archives of General Psychiatry, 4, 53-63.

Billings, A. G., \& Moos, R. H. (1984). Coping, stress and social resources among adults with unipolar depression. Journal of Personality and Social Psychology, 46, 877-891.

Blalock, J. A., \& Joiner, T. E., Jr. (2000). Interaction of cognitive avoidance coping and stress in predicting depression/anxiety. Cognitive Therapy and Research, 24, 47-65.

Bodenmann, G. (1995). A systemic-transactional view of stress and coping in couples. Swiss Journal of Psychology, 54, 34-49.

Bodenmann, G. (1997). Dyadic coping-A systemic-transactional view of stress and coping among couples: Theory and empirical findings. European Review of Applied Psychology, 47, 137-140.

Bodenmann, G. (2000). Stress und Coping bei Paaren [Stress and coping in couples]. Göttingen: Hogrefe.

Bodenmann, G., Cina, A., \& Schwerzmann, S. (2001). Individuelle und dyadische Copingressourcen bei Depressiven. [Individual and dyadic coping resources in depressed persons].Zeitschrift für Klinische Psychologie und Psychotherapie, 30, 194-203.

Bruder-Mattson, S. F., \& Hovanitz, C. A. (1990). Coping and attributional styles as predictors of depression. Journal of Clinical Psychology, 46, 557-566.

Carver, C. S., Scheier, M. F., \& Weintraub, J. (1989). Assessing coping strategies: A theoretically based approach. Journal of Personality and Social Psychology, 56, 267-283.

Coiro, M., \& Gottesman, I. I. (1996). The diathesis and/or stressor role of expressed emotion in affective illness. Clinical Psychology: Science and Practice, 3, 310-322.

Coyne, J. C. (1976). Toward an interactional description of depression. Psychiatry, 39, 28-40.

Coyne, J. C., Aldwin, C., \& Lazarus, R. S. (1981). Depression and coping in stressful episodes. Journal of Abnormal Psychology, 90, 493497.

Coyne, J. C., Kessler, R., Tal, M., Turnbull, J., Wortman, C., \& Greden, J. (1987). Living with a depressed person. Journal of Consulting and Clinical Psychology, 55, 347-352.

Cronkite, R. C., Moos, R. H., Twohey, J., Cohen, C., \& Swindle, R., Jr. (1998). Life circumstances and personal resources as predictors of the ten-year course of depression. American Journal of Community Psychology, 26, 255-280.

Dehle, C., Larsen, D., \& Landers, J. E. (2001). Social support in marriage. American Journal of Family Therapy, 29, 307-324.

Dew, M. A., \& Bromet, E. J. (1991). Effects of depression on social support in a community sample of women. In J. Eckenrode (ed.), The social context of coping (pp. 189-211). New York, NY: Plenum.

Fincham, F. D., Beach, S. R. H., \& Bradbury, T. N. (1989). Marital distress, depression, and attribution: Is the marital distress-attribution association an artifact of depression? Journal of Consulting and Clinical Psychology, 57, 768-771.

Florin, I., Nostadt, A., Reck, C., Franzen, U., \& Jenkins, M. (1992). Expressed emotion in depressed patients and their partners. Family Process, 31, 163-174.

Folkman, S., \& Lazarus, R. S. (1986). Stress processes and depressive symptomatology. Journal of Abnormal Psychology, 95, 107-113.

Gara, M. A., Woolfolk, R. L., Cohen, B. C., Goldston, R. B., Allen, L. A., \& Novalany, J. (1993). Perception of self and other in major depression. Journal of Abnormal Psychology, 102, 93-100.

George, L. K., Blazer, D. G., Hughes, D. C., \& Fowler, N. (1989). Social support and the outcome of major depression. British Journal of Psychiatry, 154, 478-485. 
Gotlib, I. H. (1982). Self-reinforcement and depression in interpersonal interaction: The role of performance level. Journal of Abnormal Psychology, 91, 3-13.

Gotlib, I. H., \& Whiffen, V. E. (1989). Stress, coping and marital satisfaction in couples with a depressed wife. Canadian Journal of Behavioral Sciences, 21, 401-418.

Haaga, D. A. F., Dyck, M. J., \& Ernst, D. (1991). Empirical status of cognitive theory of depression. Psychological Bulletin, 110, 215236.

Hahlweg, K. (1996). Fragebogen zur Partnerschaftsdiagnostik. [Partnership questionnaire]. Göttingen: Hogrefe.

Hammen, C. (1991). Generation of stress in the course of unipolar depression. Journal of Abnormal Psychology, 100, 555-561.

Hautzinger, M., Bailer, M., Worall, H., \& Keller, F. (1994). BeckDepressions-Inventar (BDI): Testhandbuch [Beck Depression Inventory: Manual]. Bern: Huber.

Henderson, A. S. (1992). Social support and depression. In H. O. F. Veiel \& U. Baumann (Eds.), The meaning and measurement of social support (pp. 85-92). New York, NY: Hemisphere.

Holahan, C. J., \& Moos, R. H. (1991). Life stressors, personal and social ressources, and depression: A 4-year structural model. Journal of Abnormal Psychology, 100, 31-38.

Hooley, J. M., \& Hahlweg, K. (1986). The marriages and interaction patterns of depressed patients and their spouses: Comparing high and low EE dyads. In M. J. Goldstein, I. Hand, \& K. Hahlweg (Eds.), Treatment of schizophrenia: Family assessment and intervention (pp. 25-34). Berlin: Springer.

Hooley, J. M., Orley, J., \& Teasdale, J. D. (1986). Levels of expressed emotion and relapse in depressed patients. British Journal of Psychiatry, 148, 642-647.

Hooley, J. M., \& Teasdale, J. B. (1989). Predictors of relapse in unipolar depressives: Expressed emotion, marital distress, and perceived criticism. Journal of Abnormal Psychology, 98, 229235 .

Horesh, N., \& Fennig, S. (2000). Perception of spouses and relationships: A matched control study of patients with severe affective disorder in remission and their spouses. Journal of Nervous and Mental Disease, 188, 463-466.

Husaini, B. A., \& Von Frank, A. (1985). Life events, coping resources, and depression: A longitudinal study of direct, buffering, and reciprocal effects. In J. R. Greenley (Ed.), Research in community and mental health (pp. 111-136). (Vol. 5). Greenwich, CT: JAI.

Johnson, S. L., \& Jacob, T. (1997). Marital interactions of depressed men and women. Journal of Consulting and Clinical Psychology, $65,15-23$.

Keitner, G. I., \& Miller, I. W. (1990). Family functioning and major depression: An overview. American Journal of Psychiatry, 147, $1128-1137$.

Kraaij, V., Garnefski, N., de Wilde, E. J., Dijkstra, A., Gehardt, W., Maes, S., et al. (2003). Negative life events and depressive symptoms in late adolescence: Bonding and cognitive coping as vulnerability factors? Journal of Youth and Adolescence, 32, 185-193.

Lakey, B., \& Cassady, P. B. (1990). Cognitive processes in perceived social support. Journal of Personality and Social Psychology, 59 $337-343$.
Lara, M. E., Leader, J., \& Klein, D. N. (1997). The association between social support and course of depression: Is it confounded with personality? Journal of Abnormal Psychology, 106, 478-482.

McCabe, S. B., \& Gotlib, I. H. (1993). Interactions of couples with and without a depressed spouse: Self-report and observations of problem-solving situations. Journal of Personality and Social Psychology, 10, 589-599.

McLean, P., \& Hakstian, A. R. (1990). Relative endurance of unipolar depression treatment effects: Longitudinal follow-up. Journal of Consulting and Clinical Psychology, 58, 482-488.

Metalsky, G. I., \& Joiner, T. E., Jr. (1992). Vulnerability to depressive symptomatology: A prospective test of the diathesis-stress and causal mediation components of the hopelessness theory of depression. Journal of Personality and Social Psychology, 4, 667-675.

Mitchell, R. E., Cronkite, R. C., \& Moos, R. H. (1983). Stress, coping and depression among married couples. Journal of Abnormal Psychology, 92, 433-448.

Monroe, M. S., Connell, M. M., Bromet, E. J., \& Steiner, S. C. (1986). Social support, life events and depressive symptoms: A 1-year prospective study. Journal of Consulting and Clinical Psychology, 54, 424-431.

Moos, R. H., Cronkite, R. C., \& Moos, B. S. (1998). The long-term interplay between family and extrafamily resources and depression. Journal of Family Psychology, 12, 326-343.

Papageorigou, C., \& Wells, A. (2003). An empirical test of a clinical metacognitive model of rumination and depression. Cognitive Therapy and Research, 27, 261-273.

Parker, G., Brown, L., \& Blignault, I. (1986). Coping behaviors as predictors of the course of clinical depression. Archives of General Psychiatry, 43, 561-565.

Perrez, M., \& Reicherts, M. (1986). Appraisal, coping and attribution processes by depressed persons: An S-R-S-R-approach. The German Journal of Psychology, 10, 315-326.

Peterson, C., \& Seligman, M. E. P. (1984). Causal explanations as risk factor for depression: Theory and evidence. Psychological Review, 91, 347-374.

Robinson, M. S., \& Alloy, L. B. (2003). Negative cognitive styles and stress-reactive rumination interact to predict depression: A prospective study. Cognitive Therapy and Reserach, 27, 275-292.

Rohde, P., Tilson, M., Lewinsohn, P. M., \& Seely, J. R. (1990). Dimensionality of coping and its relation to depression. Journal of Personality and Social Psychology, 58, 499-511.

Sandberg, J. G., \& Harper, J. M. (2000). In search of a marital distress model of depression in older marriages. Aging and Mental Health, 4, 210-222.

Sayers, L. S., Kohn, C. S., Fresco, D. M., Bellack, A. S., \& Sarwer, D. B. (2001). Marital cognitions and depression in the context of marital discord. Cognitive Therapy and Research, 25, 713-732.

Spitzer, R. L., Williams, J. B. W., Gibbon, M., \& First, M. B. (1992). The structured clinical interview for DSM-III-R (SCID): History, rationale and description. Archives of Genetics and Psychiatry, 49, $624-629$.

Vaughn, C. E., \& Leff, J. P. (1976). The measurement of expressed emotion in the families of psychiatric patients. British Journal of Social and Clinical Psychology, 15, 157-165. 